\title{
Living with Time
}

\author{
Leigh (Mean Seo) Kweon
}

Leigh Kweon is a graduate of the Bachelor of Early Childhood Care and Education program at Capilano University. She recently embarked on a new journey as a pedagogist to pursue further learning within and beyond early childhood education. Her research interests are in pedagogical work where theory and practice work together hand in hand, and reimagining early learning as collective and relational lived experiences. Email: leighkweon@gmail.com

This article researches time in the early childhood education classroom. This inquiry troubles the dominance of chronological, linear time that prescribes and predicts daily routines in a goal-oriented manner in pursuit of future development. Through this project I hope to offer alternative perspectives on time beyond modernist and neoliberal abstraction and refocus on how the learning experience can be shaped by attending to the presentness of childhoods.

Key words: time; becoming; pedagogy; pedagogy of listening; ethics of care; pedagogical inquiry
In the context of modernity, humanity has abstracted time. In the neoliberal logics of understanding time, time becomes linear and chronological as a means to measure and efficiently use it, though it largely escapes the grasp of human understanding and control. Time thus becomes an object of consumption for humans to chase after, catch up to, spend, achieve, and constantly desire (Duhn, 2016; Farquhar, 2016; Jardine, 2013; Kummen, 2010; Pacini-Ketchabaw, 2013; Rose \& Whitty, 2010; Tesar, 2016). Thus, time is abstracted, becoming an exhaustible commodity. In constructing this linear "clock-time" (Pacini-Ketchabaw, 2012), three distinct categories, past, present, and future, become the building blocks. In the "smooth functioning of industrial society" (Farquhar, 2016, p. 412)—an ideal of modernity - a sort of linear time that moves forward from the past into the future leads a way of life that is directional, predictive, and totalizing (Duhn, 2016; Farquhar, 2016).

Abstracted time also governs and dictates how we live. As future time becomes of paramount significance, past and present times are merely consumed in order to produce desirable futures. In classrooms, similar to all environments, we live in sequential times: lunchtime, naptime, snack time, outside time, etc., all of which resemble episodes that merely pass from one to the next rather than being fully lived and thought with in relation to the present. In these fragments of time, modernist understandings of time push us to only value what is forthcoming, and therefore we focus largely on the future rather than on present progress. As time passes in early childhood learning to construct some idea of the "better" future, the value of childhood on the whole is jeopardized and silenced in a society ruled by the clock. In our classrooms, we pass along this legacy of time to children, who challenge clock-time in their everyday lives. Do we live partialities of time which pass and are forgotten? What are other ways to live with time and find true value in the presentness of childhood?

In beginning a graduate research project at Capilano University, I was encouraged to sustain this interest and concern. Over the course of six months, I invited a small group of 3- to 5-year-old children in a childcare centre to be the participants of this research. The research took place on the unceded traditional territories of the Coast Salish peoples of the Musqueam, Squamish, and Tsleil-Waututh Nations, where the childcare program is situated. As an uninvited, immigrant guest to this land, I lived as both a full-time educator in the childcare centre and an undergraduate student during the time of this inquiry. I wished to acknowledge the legacies of colonization in 
my thinking throughout the inquiry and to make connections in this process with alternative ways of learning and meaning making. My effort to live time anew with the children was made possible by the reconceptualist framework thought with a group of scholars of the Reconceptualizing Early Childhood Education (RECE) Conference. For Marianne Bloch (2014), one of the main hosts of this conference, thoughts on early learning and care are led by poststructural and feminist cultural histories. The main focus of this framework is to initiate ruptures in the linearity of developmental psychology and, more fundamentally, to create opportunities to recognize different types of knowledge (Bloch, 2014). With this framework, I attempt to add a robustness to the complex nature of children's learning which, despite attempt, can be neither prescribed nor predicted. I have worked with this framework through current literature in the research of early childhood education to challenge and curate wonderings of the unquestioned governance of chronological time that we pass along to children through their education (Bloch, 2014; Duhn, 2016; Farquhar, 2016; Hohti, 2016; Jardine, 2008, 2013; Kummen, 2010; Pacini-Ketchabaw, 2012, 2013; Rose \& Whitty, 2010; Tesar, 2016; Wapenaar, 2014).

\section{Theoretical concepts}

Three main concepts made their mark on the learning journey the children and I undertook together: becoming, listening, and care - all of which are addressed by scholars of the reconceptualist philosophy. I have temporarily settled with the three concepts, which are essential in our ways of living, not only with young children, but as citizens of larger communities. Becoming, listening, and care were invited into this research and are referenced in the work of Gilles Deleuze and Félix Guattari, Carlina Rinaldi, and Gunilla Dahlberg and Peter Moss. The nomadic essence of all three concepts, which never completely settles, mobilizes learning to stay in motion. These concepts were robustly activated in this research and continue to live in our everyday lives to sustain and enrich ongoing dialogue in the classroom.

\section{Becoming}

The first main concept, becoming, began as we refocused our lens to decenter ourselves from time. Becoming is a theoretical concept referenced by the scholars Gilles Deleuze and Félix Guattari (Olsson, 2009). Becoming is an active state of learning for Deleuze and Guattari, where the learner is acquiring knowledge not only through observation or experimentation, but more intimately living with the topic of interest-in our case, time-and thus entering into a state of transformation. This transformation refers to the learner being affected by the lived experiences and entering a state of change as a result of it.

Becoming what is not ourselves (clock, forest) was not an easy or a speedy process; this process consisted of trials and errors, many pauses and hesitations. However, in our experience of becoming clock in the nap room and becoming forest that listens for the time, an opening was created for us to resituate the boundaries of our learning and understanding beyond human-centered knowledge. I feel that through this process of becoming time, we come to a deeper understanding of and relationship with the forest and are forming a greater sense of interest in our surroundings. Unravelling the mysteries of our more-than-human surroundings and multispecies relations through the concept of becoming also offers new encounters within the forest. Rather than tuning into our own world that is filled with our own thoughts, we were invited to carefully follow the lead of the trees and to practice listening to what they were willing to tell us. With becoming, our learning process digs deeper into everyday relations, allowing us to live collectively in our entanglements with the world around us and realize the potential of the more-than-human others we coexist with. 


\section{Listening}

The second guiding concept that time brought to us was listening. Listening is difficult; it is an act that cannot be satisfied in its purpose without time. In the project, listening did not happen without a struggle to spend a long time in one place. We learned that time must accompany listening in order for what is being said to fully translate. Throughout this project, I deliberately reflected on and thought with the pedagogy of listening described by Carlina Rinaldi (as explored by Dahlberg \& Moss, 2005). With the understanding of abstracted time, it feels as if time is always running out and there is not enough time for the kinds of play that do not lead to the milestones of developmental psychology (Jardine, 2013). In this lived inquiry with the children, I realized that perhaps what listening could be was an opportunity to dwell with time and linger for moments on what is heard. Having "not enough time" rushes us to hastily jump to conclusions and only desire predictable outcomes that lead to closures rather than openings. These are the ideas that were evoked from our lived experiences to nudge us toward a more ethical way of living with others and possibly teach us another meaning of care. Time allowed the pedagogy of listening to come alive. In this project, learning was not an instructed and linear process to memorize; rather, listening enabled the possibility of a living experience that created opportunities for us to realize.

Care

Care, as the last main concept that activated the research project, resonates with the theoretical concept of an ethics of care. Dahlberg and Moss (2005) express that care is not merely an empathetic practice of putting our feet in the other's shoes, but rather it is the process of staying in one's own shoes and encountering the other in the midst of differences. In our experiences in the forest, I began to see the value in encountering others and creating new streams of complex relations within the forest. We abandoned the sense of chronological time that moves ahead of us and began to live with ontological time, which is lived time. In living with time, our sensitivity to expect the unexpected was enabled. I believe this sensitivity collided with our acts of listening and created responses in acts of care toward the forest. Time evoked our sensitivity, which empowered our responsivity and perhaps even responsibility to truly care for what was speaking to us.

Care is a concept and a word that can be used redundantly in early childhood classrooms, even at the most basic level with the term child care. Time challenges the existing notion of care that has been placed upon children as a burden: to care for the classroom, to care for friends, to care for the trees, etc. Often this kind of care that asks for the child's empathy is considered to be the right thing to do. However, I would like to work with the emerging ideas from this project in conversation with the ethics of care (Dahlberg \& Moss, 2005) and seek care and responsiveness that is not merely empathy. With this idea, we must dwell with the other and respond to them in being ourselves and not anybody else. In the midst of endless differences, we enter into a realm of understanding which welcomes us to act in relation to the other while not losing ourselves in the process.

\section{Pedagogical documentation}

The main concepts that have been discussed above, becoming, listening, and care, are brought to life through lived experiences. What follows are pedagogical documentations that illustrate theory into practice and how time teaches us to live complex theories in practice. Creating pedagogical documentation signifies a sort of ethical practice in early years learning as the documentations work to amplify children's voice and ways of learning and living. Pedagogical documentation essentially narrates learning stories that invite us to take notice of the intricacies of particular ordinary moments and make meaning from the everydayness in ECE classrooms. Documentation allows both writer and reader to relive the moments illustrated and move into a more responsive 
practice that keeps the learning process alive and itinerant_creating spaces for pedagogical wonderings that align with current societal issues and entanglements. With the purpose of constructive collaboration, I shared a series of ongoing documentations at the childcare centre with the educators, children, and families to think together in building and adding to the learning journey. The documentations that follow collectively reflect the three main concepts that activated the research project, showing how our understanding and knowledge moved along a nomadic learning trajectory.

\section{Becoming}

Becoming clock. To understand the ideas that arose in my first dialogue about time with the children, I tried to invite into the nap room space what had come into our discussion about the clock: its tick-tocking sound, its circular shape, and the movement of its hands. Before inviting the children to enter the room, I created an intentional space for inquiry. I used a large rope to draw a circle on the ground to resemble the clock and turned on sounds of the clock ticking in the background. The children were then invited through the nap room doors into the newly created clock space. Excitedly entering, children stepped into the circle while some immediately gravitated toward the rope-clock on the floor. The inquiry began with the question: If you were a clock, how would you move?

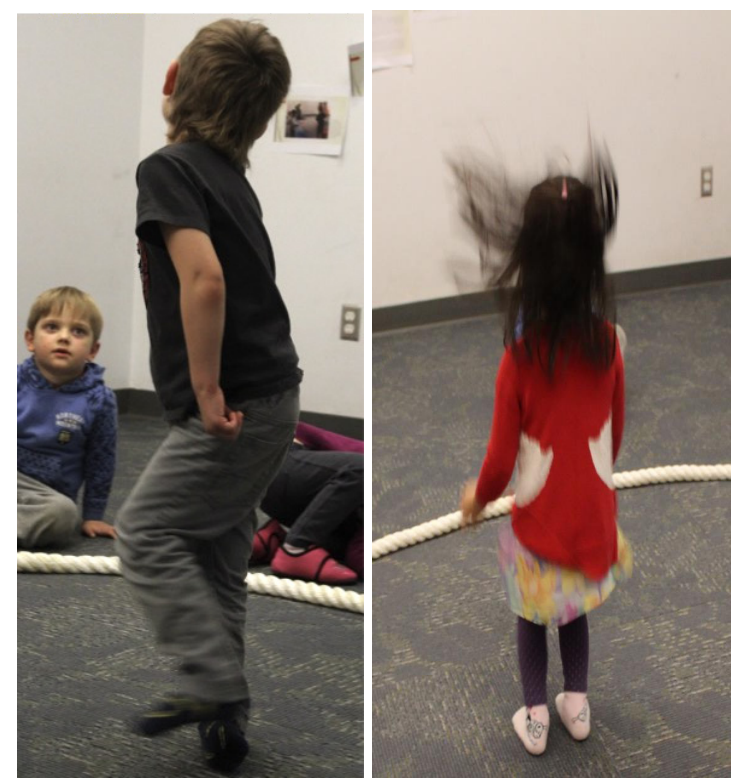

Educator: If you were a clock, how would you move?

L: I turn like this. Tick, tick, tick...

A: I jump!

Mt: I move like this. (whispering) tick ... tick ... tick...

Individual clock-bodies took turns in the circle, then one child stepped in with another.

Educator: Can clocks move together?

Mx: Well, these ones [pointing to the hands of the clock] are actually moving together.

As all five children tried to move together, the shape of the clock began to shift.

A: Uh oh, it's not a circle anymore.

Excited, the children picked up the rope, transforming the shape of the clock.

A: Mx, do you want to be tangled? 


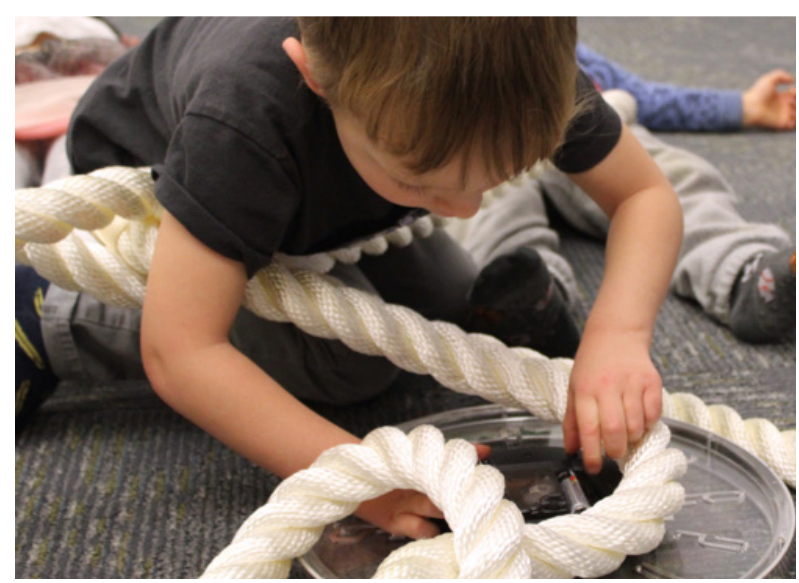

Mx nods. J: We're tangled clocks.

A: Look, Mx is stuck like a baby!

Educator: Are babies stuck?

$\mathrm{J}:$ Yes, when they are inside mommy's tummy, they are stuck. There is a clock in everybody's body.

L: There is a clock in my ear. It helps me fight germs. Right now, it's saying it is 8 o'clock.

The children's responses raised a question: In what ways had we been separating ourselves from time and living as if it were not a part of us? In this moment, I came to a realization that time also lives in us. The children, who were already aware of this, were teaching me through their ideas that time cannot be understood with mere logic. Understanding it requires feelings and a bodily awareness that tells us so much more than predictable numbers on a clock. Perhaps everyone is brought into the world with an internal clock that ticks and tocks throughout our lifetime.

In their movements and complex entanglements with the changing shape of what used to be the clock, the children were becoming tangled with time, where time is living in close relation to us (Farquhar, 2016; Hohti, 2016; Wapenaar, 2014). In becoming clock, we see that time not only can be an elusive concept but become a very real and relational idea that works-or moves, talks, and grows-with us. The children show, in their embodiment of the material, that time is never an isolated or separated concept that exists on its own but is in conversation with our bodies and our living in each moment. As the concept of becoming was activated in our research, I began to wonder: What have we been missing and letting go unnoticed in our learning as we perpetuate extensive segregation of humans from the more-than-human and claim supremacy over the latter? There seems to be a much heavier issue being raised in this moment as we reflect on the children's dialogue.

Becoming forest. Because our initial understanding of the clock was interchangeable with our understanding of time, and vice versa, I began to wonder, "How would those who do not have clocks live without time?" To inquire further with this wondering, my plan was that the children and I would head into the forest, where there are no clocks. When I offered this idea to the children, they suggested that we take the big clock (the rope) with us to the forest and become clocks again. We gladly took on the idea, and headed for the forest with full hands.

We continued our conversation about time in the forest, and our interchangeable understanding of clock and time began to unravel. In nature, and in consideration of the more-than-human bodies that live around us, the children were beginning to untie the knotted understanding of clock-time. 
S: This forest house has no clock, but time is still there.

E: How can the animals tell the time?

Al: The trees tell them [the time].

Educator: What do the trees do to tell them?

Al: They talk.

G: Yeah, the trees talk!

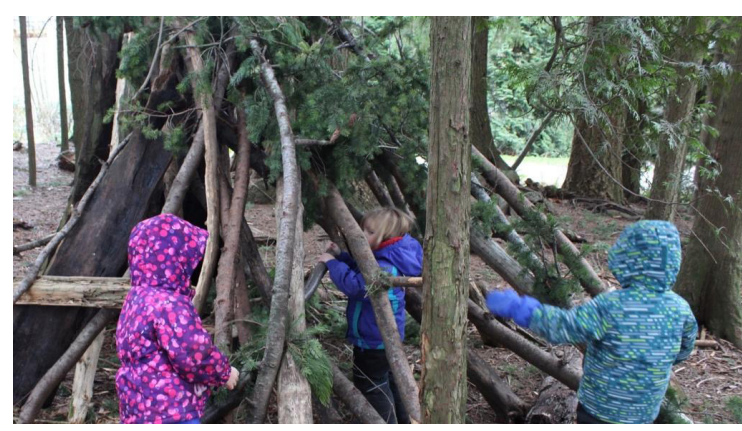

As we theorized many different ideas, the children fluidly came to an agreement that the trees "talk" to the animals to tell the time. Because the act of talking is usually complemented by the act of listening, we began to question the reciprocity of talking and listening in the forest. In becoming forest to listen for the time, our bodies were brought closer to the trees, rocks, and ground, and I noticed that becoming was slowly transforming our presence in this place.

\section{Listening}

Being with silence. In the midst of our search for time, the pedagogy of listening began to come to life. The continuing documentation consists of conversations and practices of how time invited the pedagogy of listening through our explorations in the forest. With the pauses, struggles, trials, and errors that are illustrated in the documentation, the lived experiences strengthened our roots of this learning.

Educator: If the trees talk, do you think we can hear them?

E: I don't hear anything.

G: They're not talking.

There was a pause in our exploration. As we became the forest that was trying to hear time, we felt that the trees were unresponsive to our curiosity, and we were quick to move on to what else might excite us. However, the idea of the time-telling tree lingered with me, as I believe it did for some children also. So, I continued trying hard to listen.

Then, it was in this dwelling when the dewdrops busily fell from the leaves on the trees against our hooded jackets and echoed into our ears.
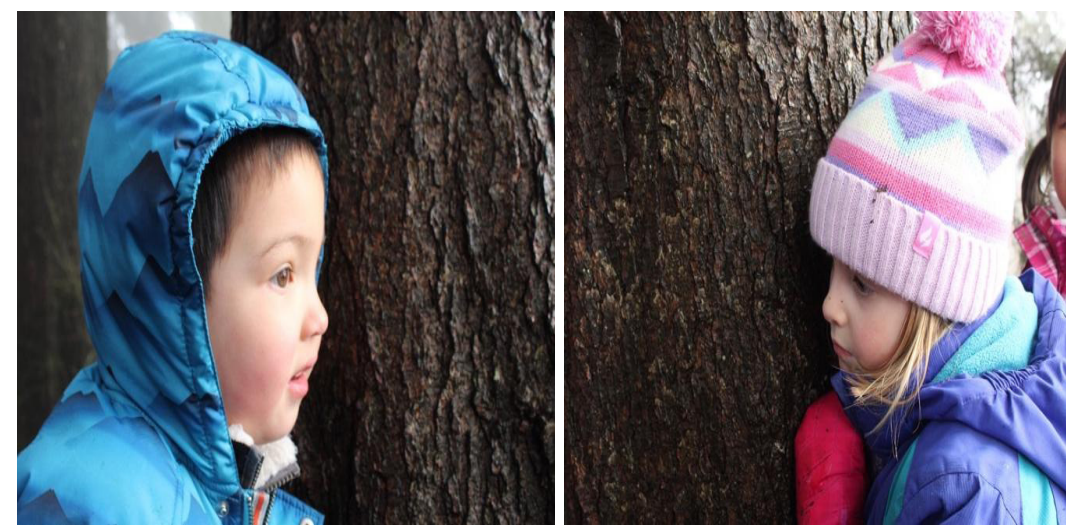

T: I hear it. It sounds like raindrops ... It's going tick tick! 
Mt: Can I hear? ... Oh yeah, you're right! Tick! Tick!

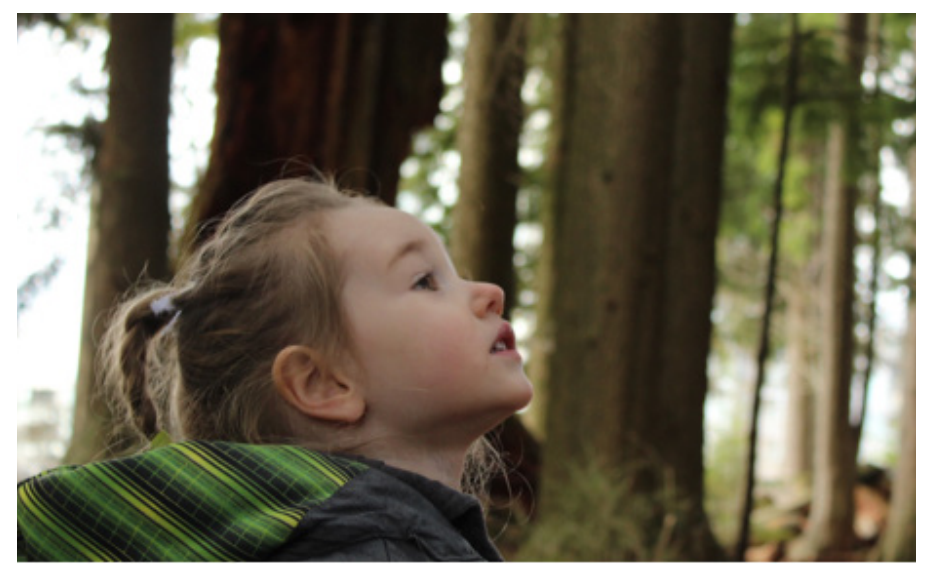

P: Everything around them tells them when to sleep.

The forest had invited each child to notice the life that resounded within.

As the act of listening spread like a contagion of ideas, $\mathrm{Mg}$ picked up a rock. Carefully, he put it against his hood-covered ear. There was a brief pause. However, $\mathrm{Mg}$ did not put the rock down, but instead hurriedly pulled off the layers that were covering his ear.
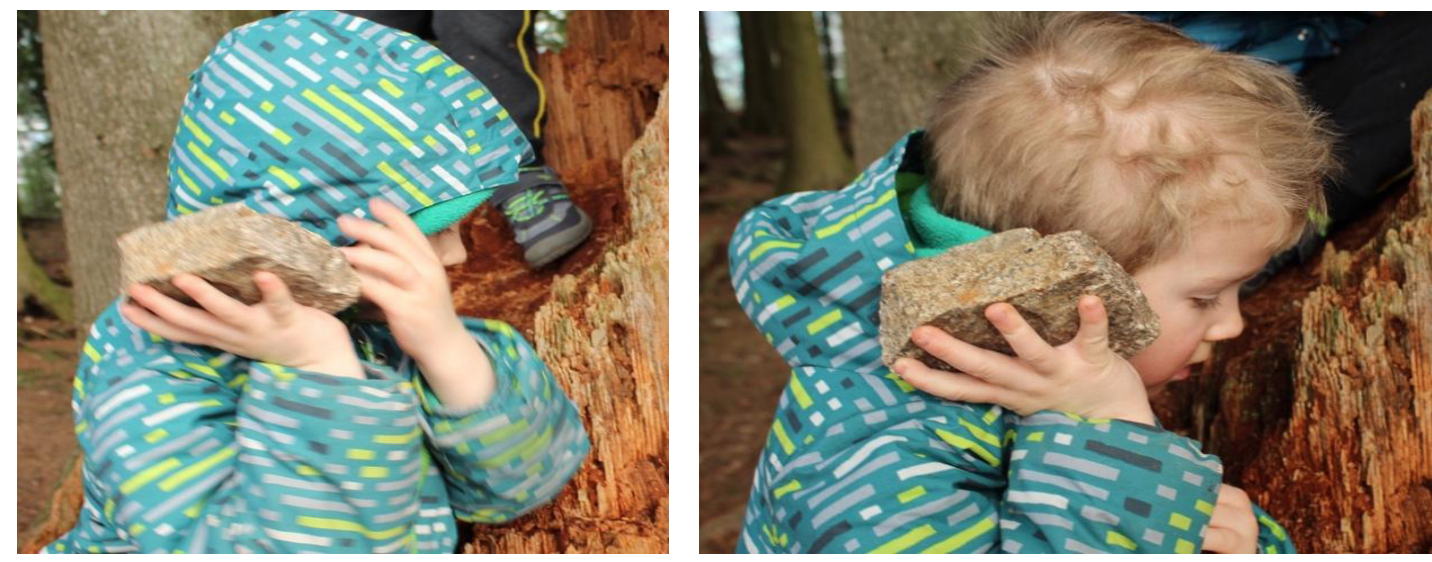

M: Oh, I think I hear something!

I believe that this moment shows us how living time with the forest taught us not only to listen to others, but also to reflect on our own being and to be transformed. Mg's act of pulling off his hood instead of putting down the rock was a transformation in Mg's presence to the forest and with the rock-it was no longer that the rock was silent or unresponsive; $\mathrm{Mg}$ realized that it was his ears that were covered and unable to hear. This realization created a rupture in our learning experience-to realize ourselves and transform, this was what lingering with time had enabled in this moment. This transformation nudges us to think about our presence in relation to more-than-human entities in our world and allows us to share a glimpse of how living reactively with morethan-human others enriches a collective learning journey.

\section{Care}

The last documentation draws on the concept of care. The following section illustrates a rich lived experience of both becoming and listening and how living with the two previous concepts led us to also live the ethics of care. The experience shows an ethics of care where children show not only an act of caring but also the heart of caring.

Time-ly responses. With the forest covered in a thick blanket of snow, we entered into a realm of peace. Before we began to search the forest for anything new, we gathered together and shared When the Trees Crackle with Cold - a children's book by Miriam Körner about how the Cree nation listens to and sees the world around them changing to know when different months and seasons come along. I hoped this book would enable our thinking 
with different ways of knowing time by listening, and that it would create an awareness of Aboriginal histories and culture of the land prior to our existence. Once the story was read, the children did not hesitate to approach the trees; however, something was different. With this knowledge of the ways of the Cree nation, listening did not merely remain a stance of waiting to hear time and move on. It was now more about reacting to what the trees actually had to tell us.

I: The trees aren't telling us anything today.

S: Oh ... Maybe they're saying it's too cold. Because of all this snow. The trees are saying that they're cold so we should brush all of this snow off for them.
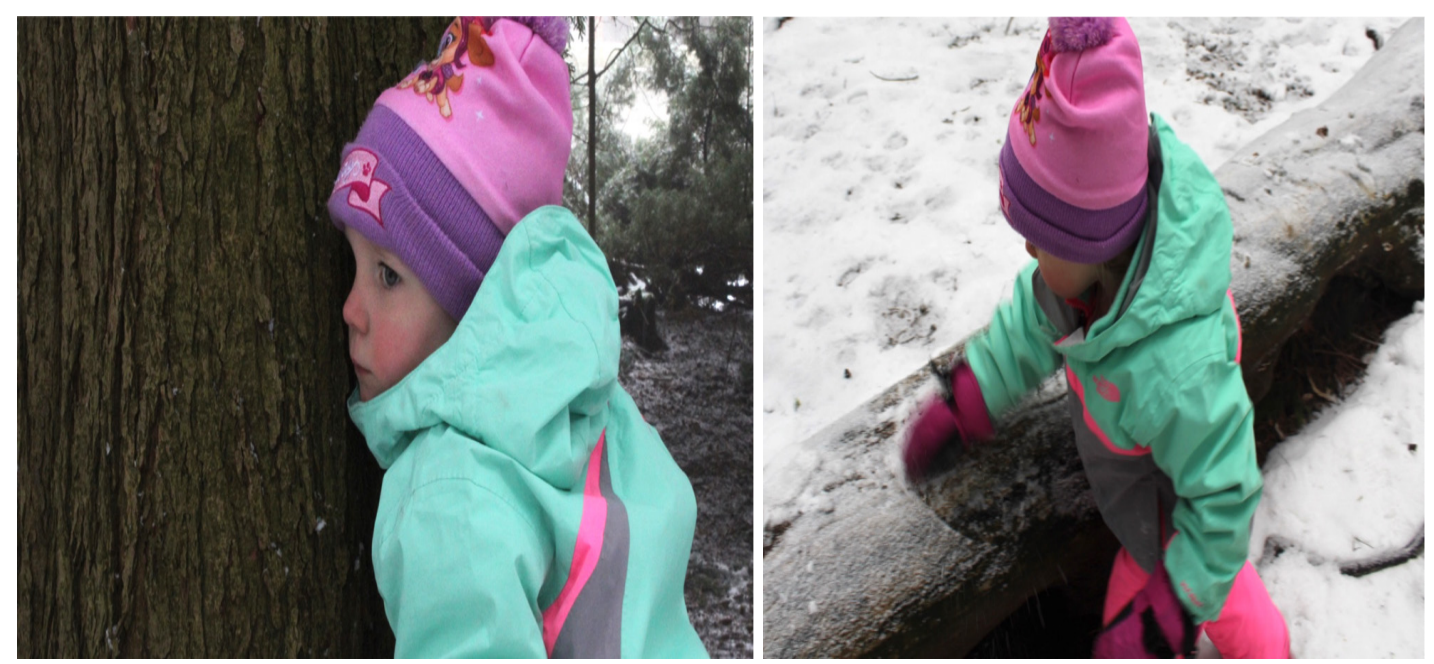

With the understanding of Aboriginal ways that spoke in conversation with the world and more-than-human others, $\mathrm{S}$ was able to actively respond. When such knowledge and awareness is carried into the world by young children and we act on this knowledge, the unwieldy politics of settler colonialism are disrupted and perhaps even agitated. Being situated on unceded territory, we cannot change history. However, by allowing these diverse colours of knowledge to seep into the ECE classroom today, learning enters a far wider and deeper paradigm of existing with others. Living with time has been teaching us many things. We continue to develop a relationship with time, a relationship that is not merely to the clock on our wall but with time that is not chronological or predictable in any sense, and in this we are developing a relationship that carefully and mutually responds to one another and walks with the other in the midst of all our differences.

Caring for the unnoticed. From our lived experiences in the forest, the children were able to bring our findings back into the classroom, inviting further entanglements. With the understanding that charcoal is a material in the classroom that has a relation to trees, the children began to make deeper connections. As we worked with charcoal to draw different ideas, stories began to flourish from the charcoal. The darkness of the charcoal called us to draw our understanding of time in the forest.

Mg: Darkness is coming! It will be dark soon. This darkness tells the time for the sick charcoal tree.

With this provocation of Darkness, the children desired to search for Darkness on our next forest visit. Where could we find Darkness that tells forest the time? 
In our walk to search for Darkness in the forest, an interesting conversation took place.

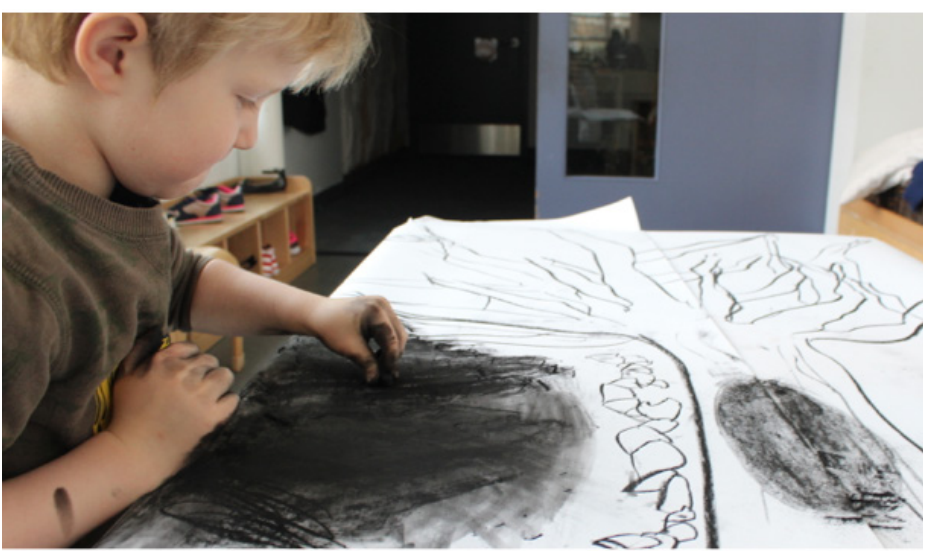

$\mathrm{J}$ : Darkness is inside your eyes.

Educator: There's darkness in our bodies?

$\mathrm{J}$ : When you're sick there is light inside, and when you are not sick there is darkness.

Mg: Yeah, right now I have light in my body because I'm a little bit sick.

Educator: How about the sick charcoal tree? It looks very dark and black. Is it still sick?

J: The darkness has to be inside. Not the outside.

This conversation led the children to search for Darkness, not only with their eyes for what was seen, but with what they could touch and feel beyond the surface. Because the search for Darkness was potentially hidden from the outside, the children tried to search for and understand Darkness with their senses. As this intuitive search continued, we realized that it was not just us who were touching. Darkness was also making its blackened mark on our fingers.

The search for darkness or time in the forest enabled us to care for the trees in a different way. We began to take notice and take time to consider what was more than meets the eye that was beyond our existing knowledge about the forest. Because we had shared the idea that it was what is on the inside of the trees that really shows the tree's well-being, our search became much more thoughtful of the forest rather than of ourselves. In this moment, the children became researchers who were living with the forest and truly learning by valuing what is in the "now." I believe that these lived moments in the forest create an opening for us to experience the complexities of time. This experience allows us to create an essence of care in our particular context in relationship to the forest. As time enabled us to step back out of the spotlight and take notice of the forest, we were living within the intricate relations of the world. Caring for others allowed us to begin realizing our potential place to belong in between these relations. In creating our own value of care respective to our particular context, learning becomes a much intensified and complex process of meaning making. This leaves us to continue seeking and coconstructing new knowledge that is alive with and continuously changing along with the world we live in.

\section{Conclusion}

These lived experiences with time became moments of living with others, being proactively responsible for one another as we lived together, and also opportunities to recognize alternative modes of learning. We took a while to dwell with the tree, the log, the stone, Darkness - to genuinely listen-and then our encounter took an additional step in which we were transformed and responded. In the process of responding, we were brought to explore our own sense of belonging in the complex relations of our surroundings. Taking the time and listening enabled us to respond to the forest and continue in dialogue with it. These moments teach us how to live with and be alive with others-more than to merely exist on our own, but to relate to others in a more responsive and caring way (Dahlberg \& Moss, 2005).

I believe that through this continuation of dwelling where children are-in the present-the predictive and linear neoliberal logic of time is deeply troubled. Time becomes continuous events of sporadic encounters with 
the other and with ourselves. There is an ongoing practice of revisiting previous pedagogical documentations, re-dwelling and re-searching these moments and bringing these moments back into the present to dig deeper into what time is teaching us. In our disturbance of chronological, future-driven time, a space was created in return that allowed us to cultivate a sense of place on the land we are situated on. Living in the now and valuing the presentness of childhoods unleashes a very complex logic. With this unconventional logic, ongoing settler colonial practice in ECE classrooms may be questioned and potentially disrupted, and we are mobilized to proactively disengage with silencing the knowledge and voices of the First Peoples of this land. The initial dwelling with clock-time led us into the forest to resituate ourselves in the network of relations with more-thanhuman others, allowing us to contextually find ourselves with the histories and inheritances of the unceded land we exist with. In these moments, time was a rhythm, and we became its melody in symphonic correlation to the world around us.

Through our lived experience with ontological time, I began to clearly see how the modernist abstraction of time in the ECE classroom limits visibility of the early learning experience. We challenged this progressing, chronological time by pausing and dwelling in the uncertainties of the present with unanswered questions, which invited us into a much more elaborate and complex network of relations. In this complexity, we created an array of entanglements, from past to present and vice versa, to co-create a contextual and collective learning experience. As I reflect on our learning journey, I see that our dwellings and wonderings led us on an unexpected course of learning that was neither linear nor predicted. In this ambiguity and unpredictable nature of our learning, we created our own understandings and values of living in a world with others. In this journey of living with time, time surprised us with many unknown routes, and now we are left with the question: What more surprises will time bring as we continue dwelling with it?

\section{Acknowledgments}

I wish to express my gratitude to all the children who participated in this research, to the educators and families for their support, and to faculty instructors of the Early Childhood Care and Education faculty at Capilano University for the ethical and pedagogical conversations that sparked the essence of this research. I extend a special appreciation to my faculty advisor for this project, Dr. Bo Sun Kim, for her guidance from the beginning of this learning journey. 


\section{Refereces}

Bloch, M. N. (2014). Interrogating reconceptualizing early care and education (RECE)-20 years along. In M. N. Bloch, B. B. Swadener, \& G. S. Cannella (Eds.), Reconceptualizing early childhood care and education (pp. 19-31). Peter Lang.

Dahlberg, G., \& Moss, P. (2005). Ethics and politics in early childhood education. RoutledgeFalmer.

Duhn, I. (2016). Speculating on childhood and time, with Michael Ende’s Momo [1973]. Contemporary Issues in Early Childhood, 17(4), 377-386. https://doi.org/10.11771463949116677922

Farquhar, S. (2016). Time in early childhood: Creative possibilities with different conceptions of time. Contemporary Issues in Early Childhood, 17(4), 409-420. https://doi.org/10.11771463949116677925

Hohti, R. (2016). Now - and now - and now: Time, space, and the material entanglements of the classroom. Children \& Society, 30(3), 180-191. https://doi.org/10.1111/chso.12135

Jardine, D. (2008). On the while of things. Journal of the American Association for the Advancement of Curriculum Studies, 9(2). https:// doi.org/10.14288/jaaacs.v4i0.187670

Jardine, D. (2013). Time is [not] always running out. Journal of the American Association for the Advancement of Curriculum Studies, 9(2). https://doi.org/10.14288/jaaacs.v9i2.187726

Kummen, K. (2010). Is it time to put "tidy up time" away? Contesting routines and transitions in early childhood spaces. In V. PaciniKetchabaw (Ed.). Flows, rhythms, and intensities of early childhood education curriculum (pp. 97-112). Peter Lang.

Pacini-Ketchabaw, V. (2012). Acting with the clock: Clocking practices in early childhood. Contemporary Issues in Early Childhood, 13(2), 154-160. http://dx.doi.org/10.2304/ciec.2012.13.2.154

Pacini-Ketchabaw, V. (2013). Politicizing transitions in early childhood. Global Studies of Childhood, 3(3), 221-229. http://dx.doi. org/10.2304/gsch.2013.3.3.221

Rose, S., \& Whitty, P. (2010). "Where do we find the time to do this?" Struggling against the tyranny of time. Alberta Journal of Educational Research, 56(3), 257-273. https://cjc-rcc.ucalgary.ca/index.php/ajer/article/view/55410

Tesar, M. (2016). Timing childhoods: An alternative reading of children's development through philosophy of time, temporality, place, and space. Contemporary Issues in Early Childhood, 17(4), 399-408. https://doi.org/10.11771463949116677924

Wapenaar, K. (2014). Entanglements of time. International Journal of Child, Youth, \& Family Studies, 5(4.2), 826-846. https://doi. org/10.18357/ijcyfs.wapenaark.5422014 